\title{
Editorial
}

\section{Periodicidade da publicação científica está com dias contados?}

\author{
Rodolfo Augusto Matteo Ambiel \\ Ana Paula Porto Noronha \\ Lucas de Francisco Carvalho \\ Universidade São Francisco - Campinas, SP, Brasil
}

A partir de 2018, a revista PsicoUSF passa a publicar seus números trimestralmente, ou seja, ao invés de três publicará quatro números por ano. Isso significa que o periódico publicará, ao menos, 14 artigos a mais por ano, diminuindo o tempo de latência entre o aceite e a disponibilização on-line do artigo. Essa ação vai ao encontro da necessidade da comunidade científica, que tem pressa que seus achados estejam disponíveis para consulta e citação de pares (Dick, Gonçalves, \& Rodrigues, 2017; Massola, Crochík, \& Svartman, 2015)). Ao mesmo tempo, percebe-se uma tendência da publicação contínua, sem a limitação das publicações por volumes ou números, ou ainda no formato on-line first. $\mathrm{Na}$ área da Psicologia de forma geral e, em especial, no Brasil, essa prática ainda parece estar em desenvolvimento, mas, nos próximos anos, com o incentivo do SciELO, possivelmente se torne mais comum e agilize o processo de publicação dos artigos científicos.

Enquanto ainda trabalhamos no formato tradicional, a Psico-USF apresenta aos seus leitores o primeiro número de 2018. Agradeçemos aos autores e pareceristas pelas contribuições. Nesse volume 23 , número 1 , são oferecidos 14 artigos inéditos de diversas temáticas que visam contribuir para a ciência da Psicologia.

Nesta edição, Single-Item Self-Esteem Scale: Brazilian Adaptation and Relationship with Personality and Prosocial Behavior é o primeiro artigo, no qual foram avaliados os parâmetros psicométricos de validade convergente de uma escala de autoestima. São autores do trabalho Carlos Eduardo Pimentel, Flávia Marcelly de Sousa Mendes da Silva, Jérssia Laís Fonseca dos Santos, Karen Guedes Oliveira, Nájila Bianca Campos Freitas, Ricardo Neves Couto e Tátila Rayane de Sampaio Brito.

Diego Eugênio Roquette Godoy Almeida, Denise de Micheli, Fernanda Davidoff Cruz e André Luiz Monezi Andrade realizaram a pesquisa intitulada Perception of Freedom in Leisure among Substance Users and Nonusers. O objetivo dos autores foi avaliar a associação entre a Percepção de Liberdade no Lazer e o uso de substâncias por adolescentes.
Children's Grief and Creativity: The Experience of Losing a Sibling é de autoria de Marcela Lança de Andrade, Fernanda Kimie Tavares Mishima-Gomes e Valéria Barbieri. O objetivo das autoras foi compreender os psicodinamismos de crianças que perderam um irmão.

A pesquisa intitulada The Stepmother-Stepchild Dyad: Narratives in the Remarriage Context teve por objetivo investigar a percepção de madrastas acerca da sua relação com seus enteados. A autoria do artigo é de Cristina Ribeiro Dantas, Terezinha Féres-Carneiro, Rebeca Nonato Machado e Andrea Seixas Magalhães.

As contribuições de Teresinha Cid Constantinidis, Laila Cristina da Silva e Maria Cristina Cardoso Ribeiro estão dispostas no artigo "Todo Mundo Quer Ter um Filho Perfeito": Vivências de Mães de Crianças com Autismo. As autoras objetivaram compreender a vivência de mães de crianças com autismo, com base em entrevistas e estudos existentes, situando o debate teórico em torno desse processo.

O objetivo das autoras Heloisa Cardoso da Silva, Milena da Rosa Silva, Giana Bitencourt Frizzo e Tagma Marina Schneider Donelli foi compreender a manifestação de sintomas psicofuncionais em bebês entre 6 e 12 meses, cujas mães apresentaram depressão. $\mathrm{O}$ título do artigo é Sintomas Psicofuncionais e Depressão Materna: Um Estudo Qualitativo.

Concepcões Parentais sobre Intencionalidade Comunicativa em Bebês aos 3 e 6 meses é o artigo cujo objetivo foi conhecer e analisar as concepções parentais referentes à intencionalidade comunicativa de bebês aos 3 e 6 meses do primeiro ano de vida. A autoria do artigo é de Laisy de Lima Nunes, Fabíola de Sousa Braz Aquino e Nádia Maria Ribeiro Salomão.

O Desenvolvimento do Bebê e sua Complexa Relação com Determinantes Sociais da Saúde é de autoria de Cristina Saling Kruel e Ana Paula Ramos de Souza. O objetivo das autoras foi averiguar a relevância dos Determinantes Sociais da Saúde para o desenvolvimento do bebê com enfoque no desenvolvimento da linguagem.

NEUPSILIN-Inf em um Modelo de Avaliação Neuropsicológica Breve para Centros de Saúde é de autoria de 
Monica Carolina Miranda, Elaine Girão Sinnes, Gislaine de Almeida Valverde Zanini, Bruna Baumgartner, Jerusa Fumagalli de Salles, Rochele Paz Fonseca e Orlando F. Amodeo Bueno. Os autores objetivaram analisar o uso do NEUPSILIN-Inf em um modelo de avaliação neuropsicológica breve em crianças atendidas em um serviço assistencial.

Similaridades e Diferenças de Crianças/Cuidadores Atendidos em Serviço-Escola de Psicologia e Psiquiatria é um estudo de Bruna de Moraes Aguiar, Renatha El Rafihi-Ferreira, Felipe Alckmin-Carvalho, Deisy Ribas Emerich e Cynthia Borges de Moura. Os autores descreveram e compararam o perfil de famílias que buscaram atendimentos em serviço-escola de Psicologia e Psiquiatria.

Suzete Rodrigues Leônidas e Cynthia de Freitas Melo realizaram a pesquisa Avaliação do Centro de Referência em Saúde do Trabalhador Cearense pelos Usuários e Representante dos Sindicatos. As autoras tiveram por objetivo avaliar o Centro de Referência em Saúde do Trabalhador (CEREST) estadual do Ceará a partir de crenças dos representantes de sindicatos e usuários.

Gabriel Lins de Holanda Coelho, Valdiney V. Gouveia, Patrícia Nunes da Fonsêca, Rafaella de Carvalho Rodrigues Araújo e Roosevelt Vilar buscaram validar a Escala de Necessidade de Pertença (ENP) para o contexto brasileiro em três estudos, sendo os dois primeiros para identificar a estrutura factorial e o terceiro para apresentar evidências de validade convergente da ENP. O artigo foi intitulado Escala de Necessidade de Pertença: Evidências de Qualidade Psicométrica.

O trabalho intitulado Evidencias de Validade da Escala de Paixão pelo Trabalho em Amostras Brasileiras é de autoria de Michelle Morelo Pereira, Maria Cristina Ferreira e Felipe Valentini. O objetivo dos autores foi adaptar a Escala de Paixão pelo Trabalho no contexto brasileiro, além de buscar evidências de validade de estrutura interna, convergente e de consistência interna.

Por fim, as autoras Brena da Cruz Prado, Fernanda Paula dos Santos Castro, Luciana Fernandes Santos, Rhayssa Ferreira Brito, Silvana Carneiro Maciel e Telma Costa Avelar buscaram traçar o perfil sociodemográfico, compreender o significado do transplante renal e o seu impacto na qualidade de vida. O título do artigo é Qualidade de Vida em Transplantados Renais.

Dick, M. E., Gonçalves, B. S., \& Rodrigues, R. S. (2017). Revista Brasileira de Design de Informação, 14(2). Recuperado de https://infodesign.emnuvens.com.br/ infodesign/article/view/595/331

Massola, G. M., Crochík, J. L., \& Svartman, B. P. (2015). Por uma crítica da divulgação científica. Psicologia USP, 26(3), doi: 10.1590/0103-656420152603 